Article

\title{
Burden of Disease Assessment of Ambient Air Pollution and Premature Mortality in Urban Areas: The Role of Socioeconomic Status and Transportation
}

\author{
Soheil Sohrabi ${ }^{1,2}$, Joe Zietsman ${ }^{2}$ and Haneen Khreis ${ }^{2,3, *}$ \\ 1 Zachry Department of Civil Engineering, Texas A\&M University, College Station, TX 77840, USA; \\ sohrabi.s@tamu.edu \\ 2 Center for Advancing Research in Transportation Emissions, Energy, and Health (CARTEEH), Texas A\&M \\ Transportation Institute (TTI), College Station, TX 77843, USA; zietsman@tamu.edu \\ 3 Barcelona Institute for Global Health (ISGlobal), Centre for Research in Environmental \\ Epidemiology (CREAL), 08003 Barcelona, Spain \\ * Correspondence: h-khreis@tti.tamu.edu
}

Received: 9 January 2020; Accepted: 5 February 2020; Published: 12 February 2020

\begin{abstract}
With recent rapid urbanization, sustainable development is required to prevent health risks associated with adverse environmental exposures from the unsustainable development of cities. Ambient air pollution is the greatest environmental risk factor for human health and is responsible for considerable levels of mortality worldwide. Burden of disease assessment (BoD) of air pollution in and across cities, and how these estimates vary according to socioeconomic status and exposure to road traffic, can help city planners and health practitioners to mitigate adverse exposures and promote public health. In this study, we quantified the health impacts of air pollution exposure $\left(\mathrm{PM}_{2.5}\right.$ and $\left.\mathrm{NO}_{2}\right)$ at the census tract level in Houston, Texas, employing a standard BoD assessment framework to estimate the premature deaths (adults 30 to 78 years old) attributable to $\mathrm{PM}_{2.5}$ and $\mathrm{NO}_{2}$. We found that 631 (95\% CI: 366-809) premature deaths were attributable to $\mathrm{PM}_{2.5}$ in Houston, and 159 (95\% CI: 0-609) were attributable to $\mathrm{NO}_{2}$, in 2010. Complying with the World Health Organization air quality guidelines (annual mean: $10 \mu \mathrm{g} / \mathrm{m}^{3}$ for $\mathrm{PM}_{2.5}$ ) and the US National Ambient Air Quality standard (annual mean: $12 \mu \mathrm{g} / \mathrm{m}^{3}$ for $\mathrm{PM}_{2.5}$ ) could save 82 (95\% CI: 42-95) and 8 (95\% CI: 6-10) lives in Houston, respectively. $\mathrm{PM}_{2.5}$ was responsible for $7.3 \%$ of all-cause premature deaths in Houston, in 2010, which is higher than the death rate associated with diabetes mellites, Alzheimer's disease, or motor vehicle crashes in the US. Households with lower income had a higher risk of adverse exposure and attributable premature deaths. We also showed a positive relationship between health impacts attributable to air pollution and road traffic passing through census tracts, which was more prominent for $\mathrm{NO}_{2}$.
\end{abstract}

Keywords: burden of disease; air pollution; premature deaths; attributable deaths; road traffic; socioeconomic inequities; United States

\section{Introduction}

About $55 \%$ of the world's population lived in urban areas in 2018, and this percentage is expected to increase to $68 \%$ by 2050 [1]. To ensure that the benefits of urbanization are equally distributed and that the risks are mitigated, urban areas need to be sustainably developed to meet population needs such as housing, transportation, health care, and other infrastructures [2]. While sustainable development of cities refers to meeting the needs of the present without compromising the ability of future generations to meet their own needs [3], unsustainable development of cities are associated with health risks for the present and future generation, including those from air pollution, climate 
change, unsafe drinking water, among others [2,4]. Despite the fact that urban air quality is a part of the assessment of sustainability of cities [4,5], according to a World Health Organization's (WHO) study on more than 4300 cities worldwide, $80 \%$ of the urban population lives in urban areas which do not comply with the WHO air quality guideline value for Particulate Matter with a diameter equal or less than 2.5 micrometers $\left(\mathrm{PM}_{2.5}\right)$ alone [6]. It has been shown that exposure to air pollution is associated with numerous health issues such as lung cancer [7], respiratory diseases [8] including chronic obstructive pulmonary disease [9], asthma [10], cardiovascular diseases [11,12], and stroke [9], to name a few. Conservative estimates from the WHO attributed 4.2 million annual deaths worldwide to ambient air pollution in 2016 [13]. Other studies showed that land transport-related air pollution, in particular, is responsible for one-fifth of deaths from air pollution in the United Kingdom, the United States (US), and Germany [14].

While burden of disease $(\mathrm{BoD})$ assessments of air pollution at national, regional, and global levels are useful, city governments, who are more agile, can only act within their jurisdictions and mitigate adverse exposures and impacts at the city level. In this context, we quantify and analyze the BoD attributable to air pollution, in the form of premature deaths, focusing on a large urban area suffering from urban sprawl and witnessing rapid population growth. We analyze the spatial variation of estimated premature deaths across the city to investigate the possible role of exposure to road traffic. The unequal distribution in health impacts of air pollution in an urban area is examined in terms of population socioeconomics.

Mortality attributable to air pollution in urban areas was quantified in a number of studies [15-20]. One study in Bradford, UK, explored and showed that the exposure to air pollution and its attributable burden of mortality inversely correlated with population socioeconomic status proxied by household income and with ethnic minorities [19]. However, no study has formally investigated whether living in areas with a higher level of road traffic correlates with the spatial variation of air pollution health outcomes. Such an analysis can be used to demonstrate the significance of road traffic in the BoD estimates when running full-chain BoD assessment models is time-consuming and cost-intensive [21].

From a methodological standpoint, previous BoD assessment studies share a similar methodology for quantifying the health burden which could be attributable to air pollution. Generally, the baseline exposure level is obtained and compared with either level of exposure recommended by health authorities or a no-exposure scenario (i.e., elimination of the exposure). Then, the relative risk of the detrimental health outcome is calculated for each exposure difference using exposure-response functions (ERF) extracted from the literature. Finally, the attributable health outcome for the population is estimated for each exposure difference using the baseline mortality rates and population data [20]. The air pollution BoD analyses have been conducted at different spatial levels including census-tract level [20,22], neighborhoods [23], lower super output area [19], and city-wide estimations [24]. The spatial level of the analysis is often dependent on the availability of data. For example, Lelieveld et al. captured the contribution of air pollution to mortality for a $100 \times 100 \mathrm{~km}$ spatial resolution [14]. Air pollution data are estimated using air quality models $[15,18-20,25]$. Different studies used different pollutants including $\mathrm{PM}_{2.5}[19,20,23]$, Nitrogen dioxide $\left(\mathrm{NO}_{2}\right)[19,26]$, and Ozone [14], where higher BoD was attributed to $\mathrm{PM}_{2.5}$ and $\mathrm{NO}_{2}$ compared to Ozone. Air pollution BoD assessment studies in cities are mainly conducted in Europe (e.g., $[15,18-20,26])$. In the US, an analysis of the health impacts of air pollution by Goodkind et al. showed that $\mathrm{PM}_{2.5}$ was responsible for 107,000 deaths in 2011 [27]. Kheirbek et al. in 2016 estimated the BoD of traffic-related PM $_{2.5}$ in New York City and examined the relation between the estimated $\mathrm{BoD}$ and poverty at the neighborhood level [23].

In our analysis, we ran a BoD assessment for two criteria air pollutants: $\mathrm{NO}_{2}$ and $\mathrm{PM}_{2.5}$, among others. $\mathrm{NO}_{2}$ and $\mathrm{PM}_{2.5}$ are traffic-related pollutants which have been associated with stronger adverse health effects including premature mortality. $\mathrm{NO}_{2}$ is, however, considered more specific to traffic-related air pollution [28]. Air pollution concentrations were estimated by a land-use regression (LUR) model and a universal kriging framework. We quantified premature deaths which could be attributable to these exposures using standard BoD assessment methodology, separately for each pollutant. The finer 
the spatial resolution of the analysis, the better the insight one can gain into health inequality issues, contributors, and high-risk spots which can be effectively targeted by policies. We, therefore, ran our analysis at the census tract level to capture spatial variations at a fine scale. To examine the health inequalities, we compared the distribution of air pollution attributable health impacts by household median income across the city. We also compared the BoD attributable to air pollution when complying with the WHO air pollutant guidelines versus the US National Abient Air Quality Standard (NAAQS) by the US Environmental Protection Agency (EPA). As a case study, we focused on the city of Houston, Texas; the fourth most populated city in the US and a rapidly growing urban area with no zoning regulations. The methodology of this study is applicable to other cities, and the results can benefit both city planners and health professionals to detect high-risk spots in cities and plan interventions accordingly. Additionally, the results can raise public awareness of the health impacts associated with air pollution and its spatial distribution across cities and promote dialogue with policymakers and other stakeholders.

\section{Materials and Methods}

\subsection{Study Setting and Definitions}

The BoD attributable to air pollution was quantified in the city of Houston for the year 2010, the year for which we had air pollution models. The city of Houston is the largest city in Texas with 636.5 square miles (1646 square $\mathrm{km}$ ) land area and 2,099,451 residents in 2010 [29]. The city is located in three US counties; Harris, Fort Bend, and Montgomery. The BoD assessment was conducted at the finest reasonable spatial resolution: the census tract level. The rationale behind assessing the $\mathrm{BoD}$ at the census tract level is twofold. First, the mortality data was only available at the county level, and so approximations were required to assign baseline mortality rates to a finer spatial level. To minimize the error of these approximations, and yet investigate the spatial distribution of health outcomes, we chose to limit the spatial resolution of this study to the census tract level. Second, analyzing the road traffic spatial variations (discussed in subsequent sections) in finer resolutaion can give a better understanding of the relation between health impacts of air pollution and road traffic. Consequently, 592 census tracts were included in this study, which were fully or partially located within Houston city's boundaries.

We quantified the health impacts in the form of attributable premature deaths. Premature death is defined as a measure of unfulfilled life expectancy [30], which is considered as the number of deaths before reaching the expected age of death in a population. The life expectancy in the US was 78.7 years old in 2010 [31]. The risks of mortality in association with $\mathrm{NO}_{2}$ and $\mathrm{PM}_{2.5}$ were sourced from meta-analysis studies for individuals older than 30 years old (details are provided in subsequent sections). Hereafter, the term premature death refers to the death of individuals aged 30 to 78 years old who died in a natural way (as opposed to accidents and suicides).

\subsection{Input Data}

The data used in this study were collected from multiple sources-namely, the US census bureau, Centers for Disease Control and Prevention, and Texas Department of Transportation, as described in the following sections.

\subsubsection{Population, Socioeconomic, and Geographic Data}

Population and socioeconomic data were collected from the US Census Bureau for 2010 at the census tract level along with the census tracts' geographic characteristics. We stratified the estimated BoD by household economy using the median household income at the census tract level, as sourced from the US Census Bureau. The average households' median income in the city of Houston, in 2010, was 52,857 dollars. City of Houston geographical limits was sourced from the city's open data portal which was used to identify the census tracts within the city's boundaries (retrieved from https://cohgis-mycity.opendata.arcgis.com/datasets/houston-city-limit). 


\subsubsection{Mortality Data}

The baseline mortality data for Texas in the year 2010 was sourced from the Centers for Disease Control and Prevention (CDC) (https://wonder.cdc.gov/mcd.html). The mortality data was available both in the form of the number of deaths and crude mortality rates (Crude mortality rate is the total number of deaths of residents in a county divided by the total population for the county (for a calendar year) and multiplied by 100,000 ) at the county level with $95 \%$ confidence intervals (CI). To quantify premature deaths attributable to air pollution, the number of all-cause natural deaths for people aged 30-78 years old was used in this study. Given that the city of Houston is located in three counties: Harris, Fort Bend, and Montgomery, the mortality data for these three counties was collected. We distributed the number of mortality cases (available at the county level) across census tracts proportionally based on their population size. In 2010, a total number of 8667 all-cause premature deaths (natural deaths excluding accidental mortalities) were reported in the city of Houston (30-78 years old). The summary statistics of the mortality data at the census tract level are reported in Table 1.

Table 1. Summary statistics of input data.

\begin{tabular}{cccccc}
\hline Variable & Sample Size (Census Tracts) & Min & Median & Mean & Max \\
\hline All-cause premature deaths (persons) & 592 & 1 & 14 & 15 & 61 \\
$\mathrm{NO}_{2}$ concentration $\left(\mu \mathrm{g} / \mathrm{m}^{3}\right)$ & 592 & 7.47 & 19.38 & 19.52 & 34.09 \\
$\mathrm{PM}_{2.5}$ concentration $\left(\mu \mathrm{g} / \mathrm{m}^{3}\right)$ & 592 & 6.80 & 11.61 & 11.41 & 13.30 \\
VMTA (veh.mi $\left./ \mathrm{mi}^{2}\right)$ & 592 & 0.72 & 99.27 & 163.04 & 1077.54 \\
Median household income (dollar) & 592 & 9926 & 43,352 & 52,857 & 214,861 \\
\hline
\end{tabular}

\subsubsection{Air Pollution Data}

$\mathrm{NO}_{2}$ and $\mathrm{PM}_{2.5}$ concentrations were sourced from a previously published and validated LUR model and a universal kriging framework, also employed in our previous study [32]. We used the annual average concentrations in $\mu \mathrm{g} / \mathrm{m}^{3}$ for the year 2010 at the centroid of each census tract. The data was originally estimated at the centroid of the census blocks which are one level smaller than census tracts. We assigned the area-weighted average of concentrations at census blocks (that are contained within each census tract) to census tracts. $\mathrm{NO}_{2}$ concentrations were converted from $\mathrm{ppb}$ to $\mu \mathrm{g} / \mathrm{m}^{3}$ through multiplying by 1.88 [33]. Table 1 provides a detailed summary of pollutant concentrations across the city. The spatial distribution of air pollutants is also shown in Figure 1. In the following, we briefly discuss the models used for estimating $\mathrm{NO}_{2}$ and $\mathrm{PM}_{2.5}$ concentrations.

The $\mathrm{NO}_{2}$ estimates were obtained from a LUR model, developed by Bechle et al. [34]. In brief, the model uses satellite data and EPA air quality monitor readings of $\mathrm{NO}_{2}$ concentrations, alongside several covariates (for example, impervious surfaces, elevation, major roads, residential roads, and distance to the coast) to estimate $\mathrm{NO}_{2}$ concentrations. The final model we used has a relatively high predictive power at unmeasured locations which was tested using a hold-out cross-validation with good model performance $\left(\mathrm{R}^{2}=0.82\right)$; which is comparable with other continental-scale $\mathrm{NO}_{2} \mathrm{LUR}$ models [35-37].

On the other hand, annual average concentrations of $\mathrm{PM}_{2.5}$ were estimated using data from 17 years (1999-2015). The data were derived from regulatory monitors and estimates were constructed in a universal kriging framework [38]. Partial least squares were estimated for model performance from hundreds of geographic variables, including land use, population, and satellite-derived estimates of land use and air pollution. Hold-out cross-validation (CV) indicated good model performance (10-fold $\mathrm{CV}-\mathrm{R}^{2}=0.85$ ). Annual $\mathrm{PM}_{2.5}$ concentrations were estimated at the census tract centroids (with similar procedure as described above). 


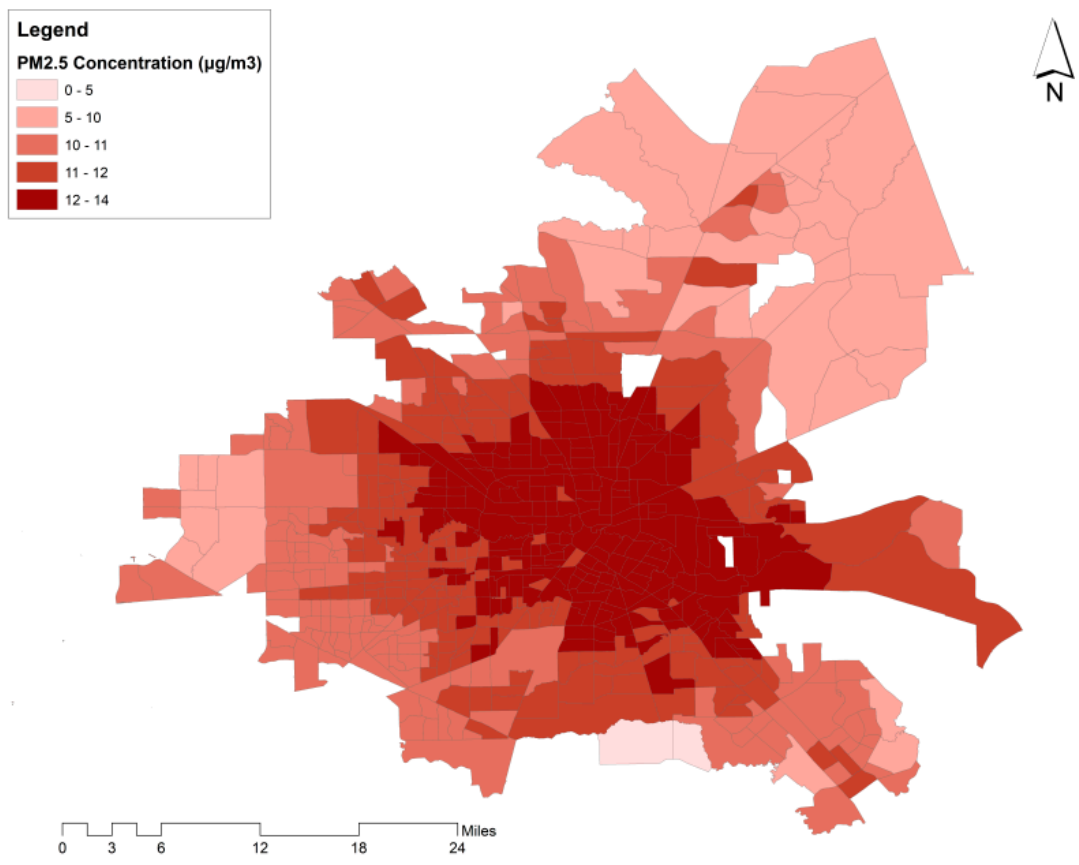

(a)

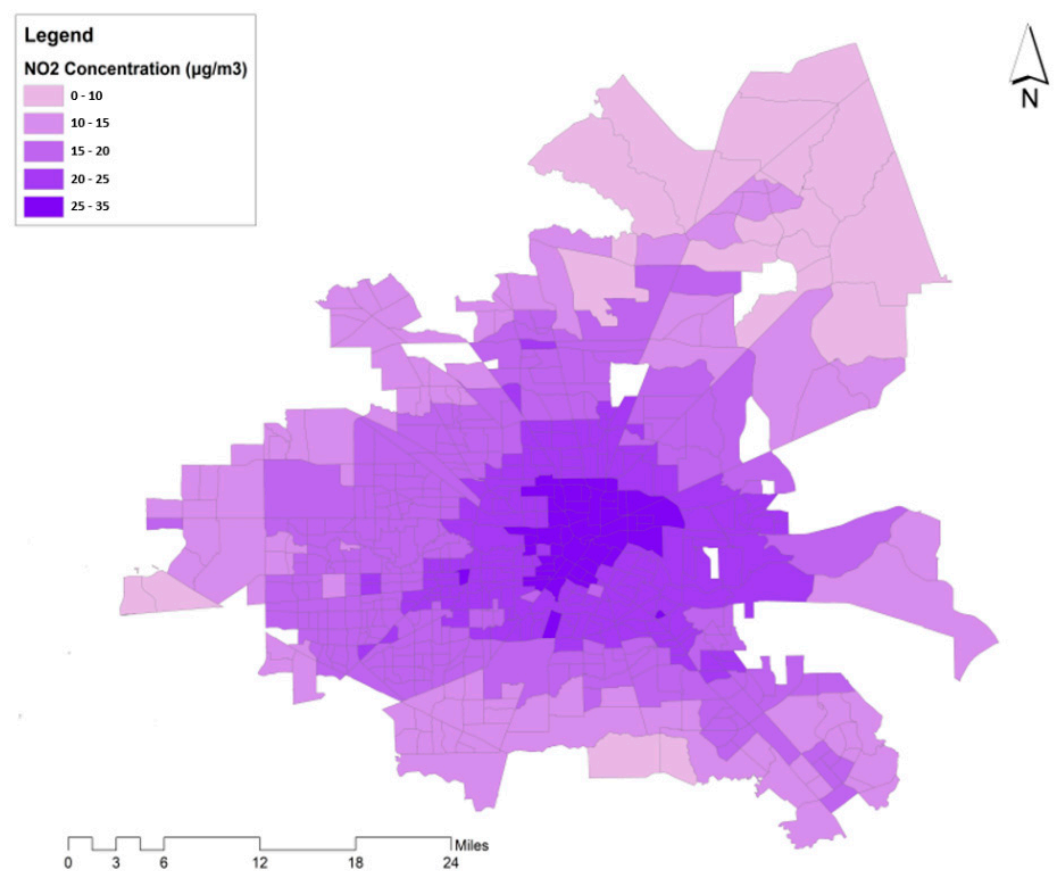

(b)

Figure 1. (a) $\mathrm{PM}_{2.5}$ and (b) $\mathrm{NO}_{2}$ annual average concentrations across the city of Houston at the census tract level, in 2010.

\subsubsection{Road Traffic}

In this study, the annual averaged daily vehicle mile traveled per area (VMTA) was used to investigate the relation between road traffic and the air pollution health burden, at the census tract 
level. VMTA represents the density of vehicle mile traveled (VMT) at a census tract. The vehicle mile traveled (VMT) was calculated by aggregating the multiplication of the road segment length and annual daily traffic (ADT) passing through all road segments located within a census tract. Then, the VMT was divided by the census tract's area. Equation (1) shows the VMTA calculation for each census tract:

$$
\text { VMTA }=\frac{\text { ADT.Road Length }}{\text { Census Tract Area }}\left(\frac{\text { veh.mi }}{\mathrm{mi}^{2}}\right)
$$

In addition to the roads located within the census tract, the possible impacts of roads near the census tract's boundary were taken into account. According to the $\mathrm{WHO}, \mathrm{PM}_{2.5}$, and $\mathrm{NO}_{2}$ concentrations decrease to background concentrations within 100-150 m (328-492 feet) of a roadway [39]. To this end, we included the VMT passing through all roads within 492 feet distance of the census tract's boundary to estimate the VMTA of that census tract.

We identified the roads located within a 492 feet distance of the census tract boundary using ArcGIS and included those in VMTA calculations. Road network and ADT data were sourced from the Texas roadway inventory data by the Texas Department of Transportation (https://www.txdot.gov/ inside-txdot/division/transportation-planning/roadway-inventory.html). The data was not available for 2010, and therefore, the ADT data from 2011 was used. We assumed that the spatial distribution of road traffic across census tracts is consistent between 2010 and 2011. A summary of road traffic statistics is presented in Table 1.

\subsection{Burden of Disease Assessment Model}

We used a standard $\mathrm{BoD}$ assessment framework previously developed in the literature [20]. In brief, the inputs to the $\mathrm{BoD}$ model included the $\mathrm{NO}_{2}$ and $\mathrm{PM}_{2.5}$ concentrations, as well as the baseline all-cause death rate in the studied region. Next, the Relative Risk $\left(\mathrm{RR}_{\text {diff }}\right)$ of all-cause mortality in association with the difference between current concentrations and the counterfactual concentrations were estimated. Equation (2) presents the $R_{\text {diff }}$ calculations for a linear ERF.

$$
R R_{\text {diff }}=R R \times \frac{\left(E_{\text {current }}-E_{\text {counterfactual exposure }}\right)}{R R_{\text {unit }}}
$$

where $R R$ is the relative risk as extracted from the literature, $E_{\text {current }}$ represents the current concentration level, $E_{\text {counterfactual exposure }}$ represents the counterfactual exposure level, and $R_{\text {unit }}$ is the exposure unit of RR obtained from the original ERFs. Then, the population attributable fraction (PAF) was calculated using Equation (3). The PAF represents the ratio of premature deaths attributable to air pollutants from all-cause deaths for the difference between current exposure levels and the counterfactual exposure levels.

$$
\mathrm{PAF}=\frac{\mathrm{RR}_{\mathrm{diff}}-1}{\mathrm{RR}_{\text {diff }}}
$$

Finally, the attributable deaths were estimated using the mortality rate and population counts for people aged 30-78 years old, and the estimated PAF (using Equation (4)). The employed BoD assessment framework is presented in Figure 2. This procedure was used for estimating the attributable premature deaths across the 592 census tracts, separately for each pollutant.

$$
\text { Attributabl Mortality }=\mathrm{PAF} \times \text { Mortality rate } \times \text { Population counts }
$$




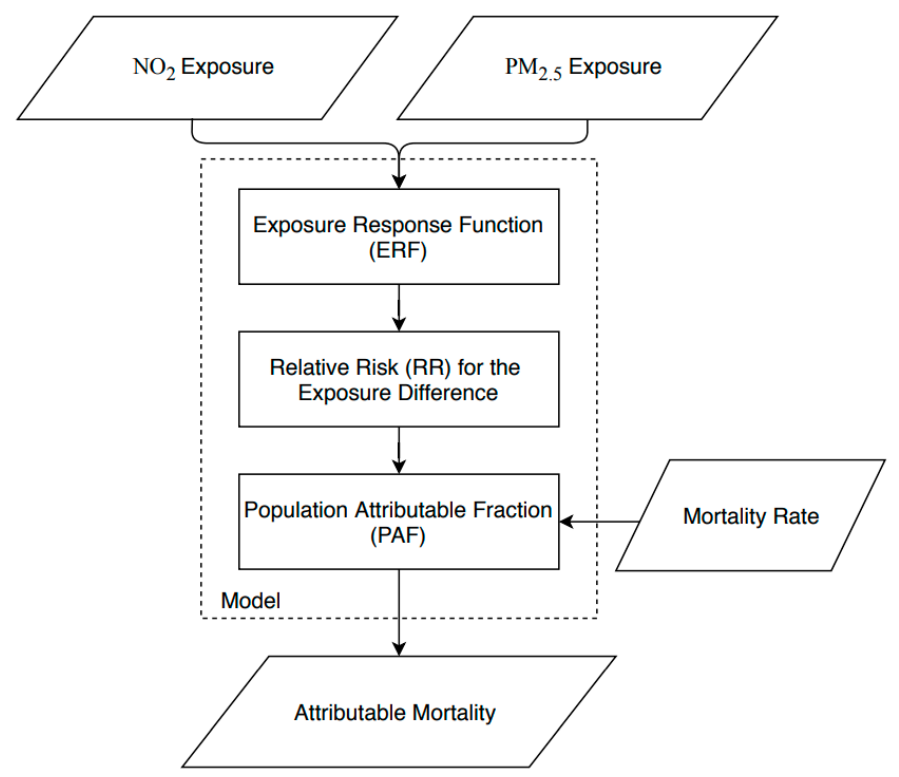

Figure 2. Burden of disease assessment framework.

\subsection{Exposure-Response Functions}

We extracted the ERF for $\mathrm{NO}_{2}$ and $\mathrm{PM}_{2.5}$ from two meta-analyses. The first meta-analysis included data from 22 cohort studies with a total of 367,251 participants and was used for the ERF of $\mathrm{NO}_{2}$ and mortality [40]. Based on the documented ERF which associated natural deaths with $\mathrm{NO}_{2}$, the RR of deaths per $10 \mu \mathrm{g} / \mathrm{m}^{3} \mathrm{NO}_{2}$ was estimated as 1.02 (95\% CI: 0.99-1.04) for individuals older than 30 years. This RR was adjusted for sex, calendar time, smoking status, smoking intensity, smoking duration, environmental tobacco smoke, fruit intake, vegetable intake, alcohol consumption, body-mass index (BMI), educational level, occupational class, employment status, marital status, and area-level socioeconomic status [40]. Note that the lower limit of the RR: 0.99 implies that no adverse health effect is associated with $10 \mu \mathrm{g} / \mathrm{m}^{3}$ increase in $\mathrm{NO}_{2}$ exposure.

The ERF for $\mathrm{PM}_{2.5}$ was extracted from a meta-analysis by WHO [41]. This meta-analysis was performed on 14 studies and resulted in RR for different regions. For the US, using a linear ERF, the overall RR of natural deaths associated with $\mathrm{PM}_{2.5}$ was estimated as 1.07 (95\% CI: 1.02-1.12) per 10 $\mu \mathrm{g} / \mathrm{m}^{3}$ for individuals 20 years and older. The RR was not adjusted for the impact of $\mathrm{NO}_{2}$ and as such, we estimated the burden from both pollutants separately and emphasize that these should not be added up [41].

\subsection{Counterfactual Scenario}

We estimated premature deaths attributable to air pollution for three counterfactual scenarios:

1. Zero-exposure of the population to air pollution,

2. Air pollution concentrations complying with the WHO air quality guideline values, where in exceedance.

3. Air pollution concentrations complying with the the US NAAQS, where in exceedance.

In the first scenario, the current concentrations, as estimated from the air pollution models, were compared to zero concentrations to demonstrate the overall $\mathrm{BoD}$ of ambient air pollution in the city. Note that the zero-exposure scenario is not a realistic scenario and is only defined for comparison purposes. In the second scenario, the current concentrations were compared to the WHO air quality guideline values. WHO recommends that $\mathrm{NO}_{2}$ does not exceed $40 \mu \mathrm{g} / \mathrm{m}^{3}$ annual mean and $\mathrm{PM}_{2.5}$ does not exceed $10 \mu \mathrm{g} / \mathrm{m}^{3}$ annual mean [33]. In the third scenario, we compared the current concenterations with the US NAAQS, established by the US EPA. The NAAQS annual average limits for $\mathrm{NO}_{2}$ and 
$\mathrm{PM}_{2.5}$ are 99 [42] and $12 \mu \mathrm{g} / \mathrm{m}^{3}$ [43], respectively. The RR of mortality in association with $\mathrm{NO}_{2}$ and $\mathrm{PM}_{2.5}$ was rescaled for the difference between the current concentration levels and the counterfactual concentration levels, as shown in Equation (2).

\subsection{Sensitivity Analysis}

Uncertainties are inherited in variables incorporated in $\mathrm{BoD}$ assessment studies, mainly arising from the uncertainty in the baseline health data and the selected ERFs, among others. To explore the range of uncertainty from the variables included in our analysis, including the baseline mortality and ERFs, we ran two uncertainty analyses. First, we estimated the most conservative and most extreme BoD scenarios using the combinations of the lower and upper $95 \% \mathrm{CI}$ for each of the variables above (baseline mortality and ERFs). These two scenarios are reported in parentheses after the central estimated values of premature deaths attributable to air pollution. Second, we examined the impacts of uncertainty in input data for each variable on premature death estimations. To this end, we reran the analysis for upper and lower $95 \% \mathrm{CI}$ of each variable, individually, and reported the estimated premature deaths.

\section{Results}

\subsection{Premature Deaths Attributable to Air Pollution}

Table 2 summarizes the estimated premature deaths attributable to $\mathrm{NO}_{2}$ and $\mathrm{PM}_{2.5}$ in the city of Houston, in 2010. A total of 631 premature deaths for the age group between 30 and 78 years old were attributable to $\mathrm{PM}_{2.5}$. Considering the most conservative and the most extreme BoD scenarios, the number of premature deaths attributable to $\mathrm{PM}_{2.5}$ varied from 366 to 809 deaths. Similarly, 159 (95\% CI: 0-609) premature deaths were attributable to $\mathrm{NO}_{2}$. Exceeding the WHO air quality guideline values resulted in 82 (95\% CI: 42-95) preventable premature deaths attributable to $\mathrm{PM}_{2.5}$. Additionally, 8 (95\% CI: 6-10) premature deaths may be attributable to $\mathrm{PM}_{2.5}$ exceeding the NAAQS.

Table 2. Premature deaths attributable to air pollution in Houston.

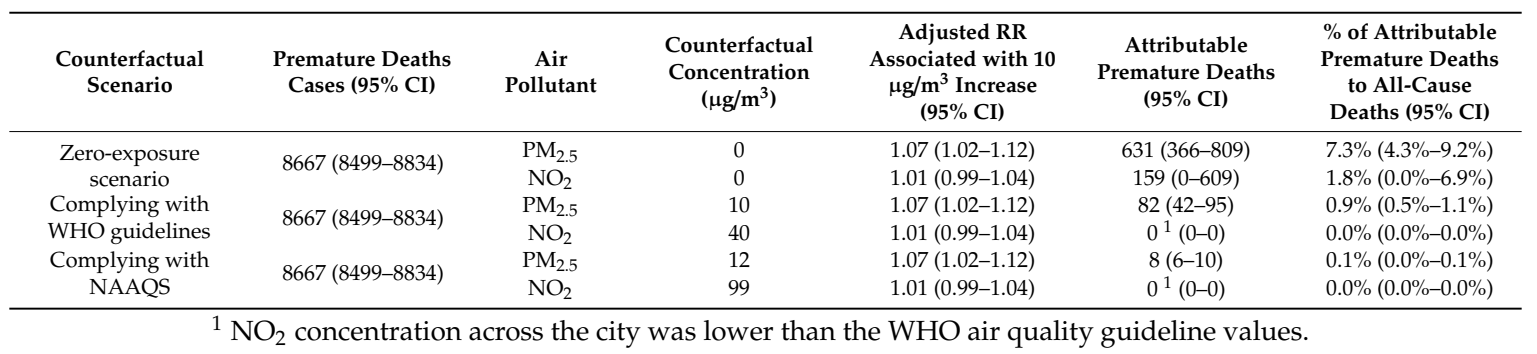

Figure 3 illustrates the range of the percentage of premature deaths attributable to air pollution (zero-exposure scenario) from all-cause deaths and its distribution across census tracts. The spatial distribution of premature deaths attributable to $\mathrm{PM}_{2.5}$ and $\mathrm{NO}_{2}$ (zero-exposure scenario) across census tracts is shown in Figure $4 a, b$, in the form of a percentage from all-cause premature deaths. The percentage of premature deaths attributable to $\mathrm{NO}_{2}$ was higher in census tracts located in the central business district (CBD). Additionally, a spatial similarity is observed between the distribution of air pollutants' health impacts and VMTA (Figure 4c). 


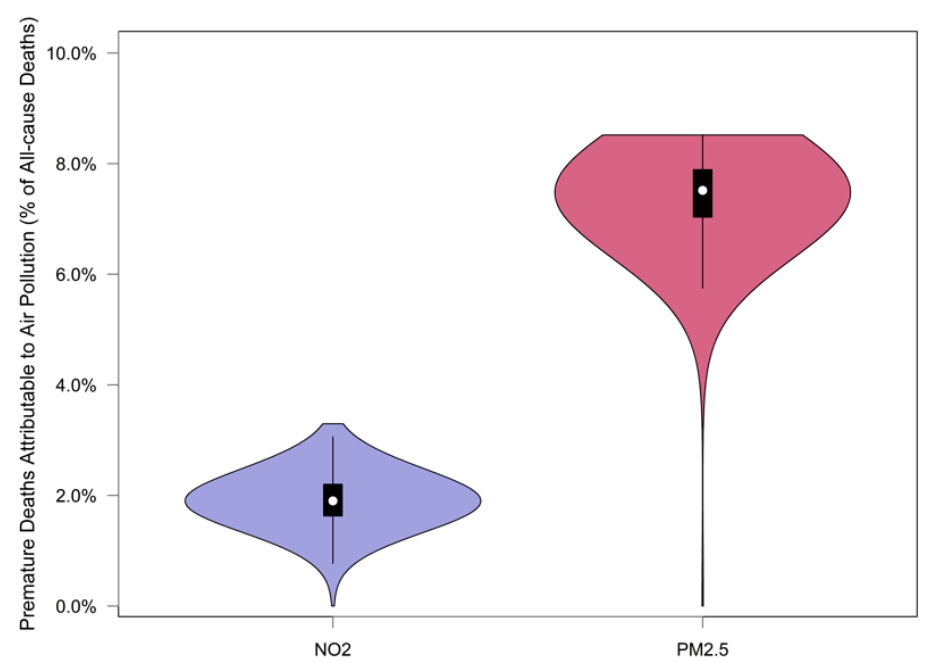

Figure 3. Range and distribution of estimated premature deaths attributable to $\mathrm{PM}_{2.5}$ and $\mathrm{NO}_{2}$ as a percentage from all-cause deaths for zero-exposure scneario.

\subsection{Premature Deaths Attributable to Air Pollution by Household Income and Road Traffic}

Figure $4 \mathrm{~d}$ shows the spatial variation of median household income across the city. The relation between median household income at each census tract and premature deaths attributable to air pollution was further explored. The comparison showed an inverse correlation between median household income at the census tract level and the ratio of premature deaths attributable to air pollution from all-cause premature deaths (the average lines in Figure 5a). In other words, it is expected that the ratio of premature deaths attributable to $\mathrm{PM}_{2.5}$ and $\mathrm{NO}_{2}$ reduces (by $10 \%$ of the estimated ratio (Figure 5a)) with an increase in household income from $\$ 20,000$ to $\$ 75,000$.

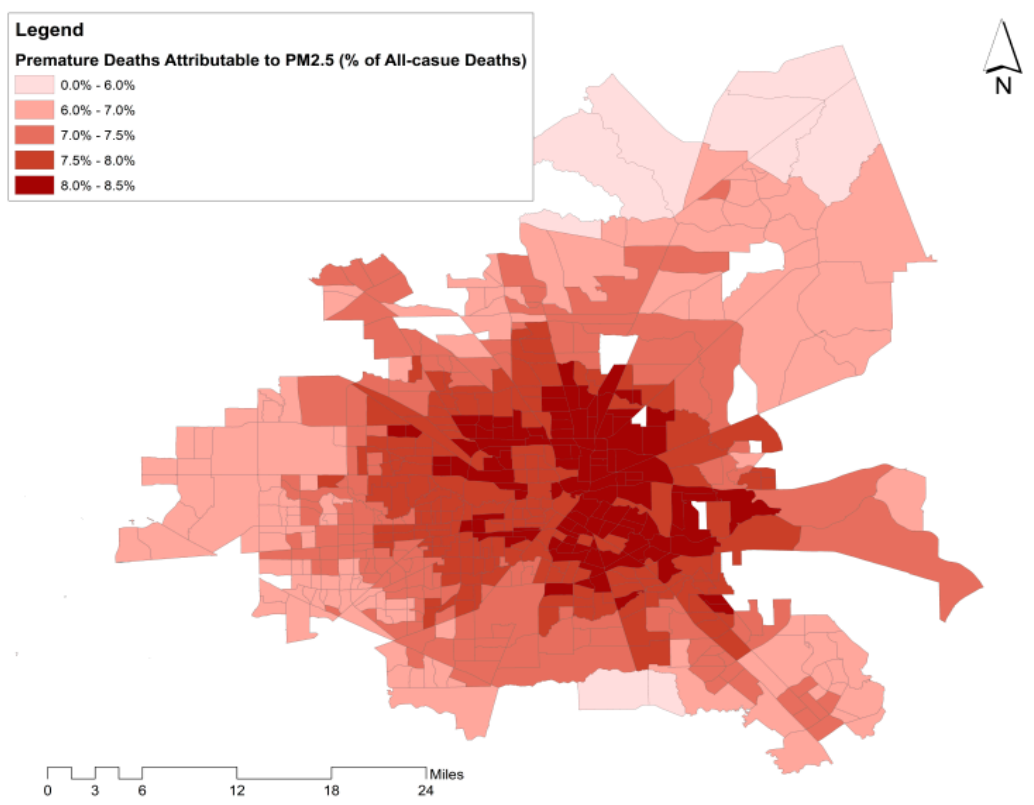

(a)

Figure 4. Cont. 


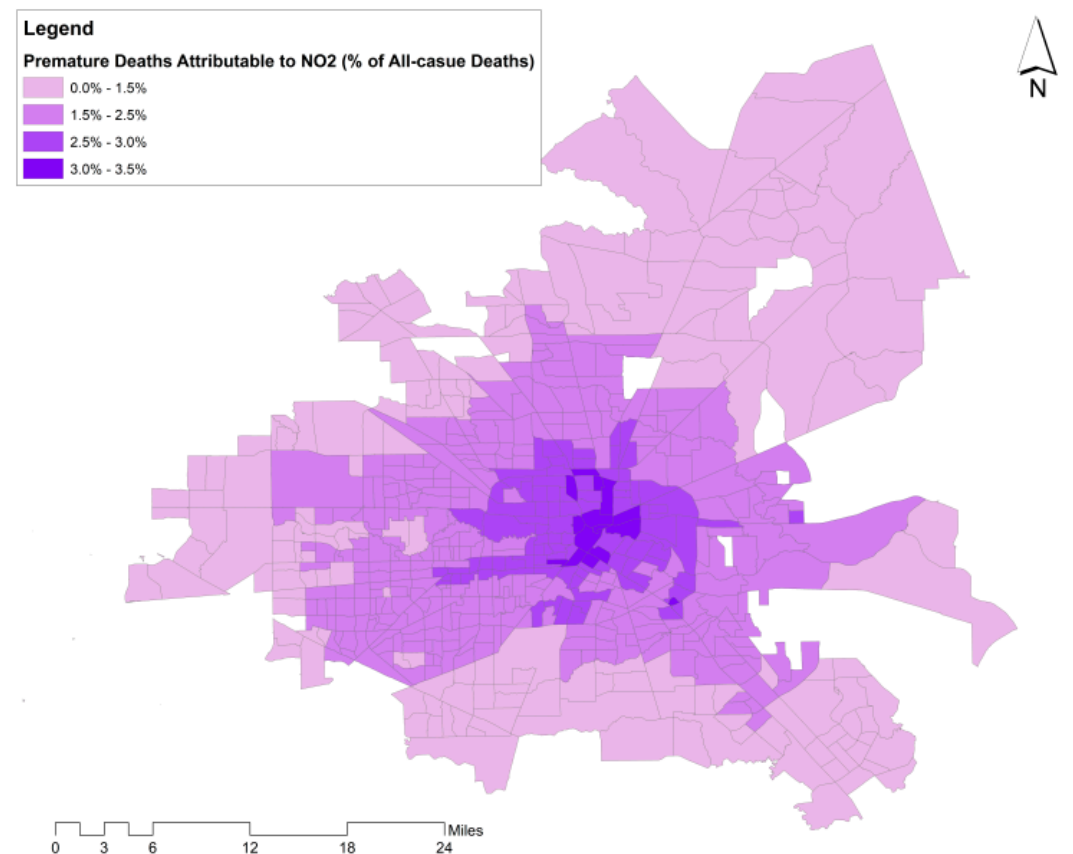

(b)

\begin{tabular}{l} 
Legend \\
Vehicle Mile Traveled per Area (VMT/sq. mi) \\
$0-75$ \\
$75-150$ \\
$150-300$ \\
$300-450$ \\
$450-1100$ \\
\hline
\end{tabular}

$\Delta$

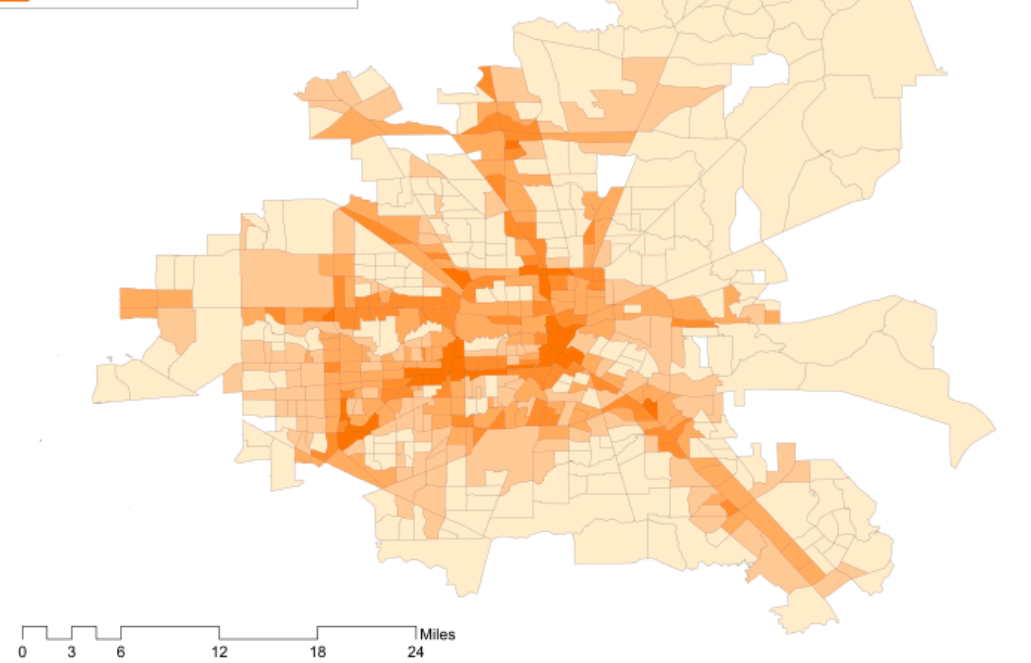

(c)

Figure 4. Cont. 


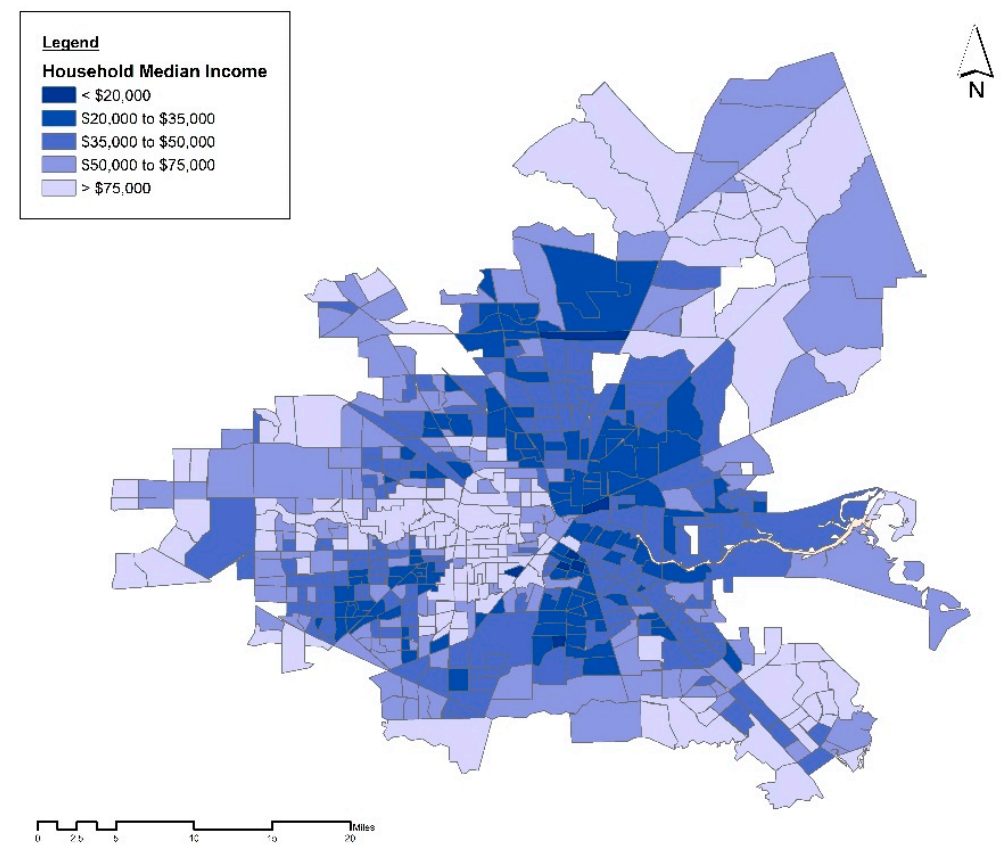

(d)

Figure 4. Spatial variation of (a) percentage of premature deaths attributable to $\mathrm{PM}_{2.5}$ from all-cause deaths, (b) percentage of premature deaths attributable to $\mathrm{NO}_{2}$ from all-cause deaths across the city of Houston at the census tract level, in 2010. Spatial variation of (c) vehicle mile traveled per area, and (d) median household income across the city of Houston at the census tract level, in 2010.

According to Figure 3, the ratio of premature deaths attributable to $\mathrm{PM}_{2.5}$ and $\mathrm{NO}_{2}$ at the census tract level can vary from $0.0 \%$ to $3.3 \%$ and $0.0 \%$ to $8.6 \%$, respectively. After a closer look at the spatial distribution of the ratio of premature deaths across the city, a relationship between VMTA and the ratio of premature deaths attributable to air pollutants was shown (illustrated in Figure 5b). This relationship is consistent with the similarity between the spatial variation of the premature deaths attributable to air pollutants and VMTA indicated in Figure 4. The relation between the ratio of premature deaths and VMTA is stronger for the deaths estimated due to $\mathrm{NO}_{2}$ compared to $\mathrm{PM}_{2.5}$ (R-squared of the best-fitted curve for $\mathrm{NO}_{2}$ is 0.52 versus 0.23 for $\mathrm{PM}_{2.5}$ ).

\subsection{Sensitivity Analysis}

The most conservative estimation of premature deaths attributable to $\mathrm{NO}_{2}$ resulted in zero deaths. The most extreme estimation resulted in 609 deaths (Table 2). The most conservative and most extreme estimations for premature death attributable to $\mathrm{PM}_{2.5}$ resulted in 366 and 809 deaths.

Results of the uncertainty analysis of lower and upper 95th CI of each variable is depicted in Figure 6. The $95 \% \mathrm{CI}$ of ERFs had the largest role in the uncertainty of estimated deaths, where the estimated attributable premature deaths due to $\mathrm{NO}_{2}$ and $\mathrm{PM}_{2.5}$ could be changed by up to $276.1 \%$ and $41.0 \%$, respectively. The uncertainties in the mortality rates resulted in up to $2.1 \%$ deviation in the estimated attributable premature deaths. Overall, more uncertainty was associated with premature death attributable to $\mathrm{NO}_{2}$ compared to $\mathrm{PM}_{2.5}$. 


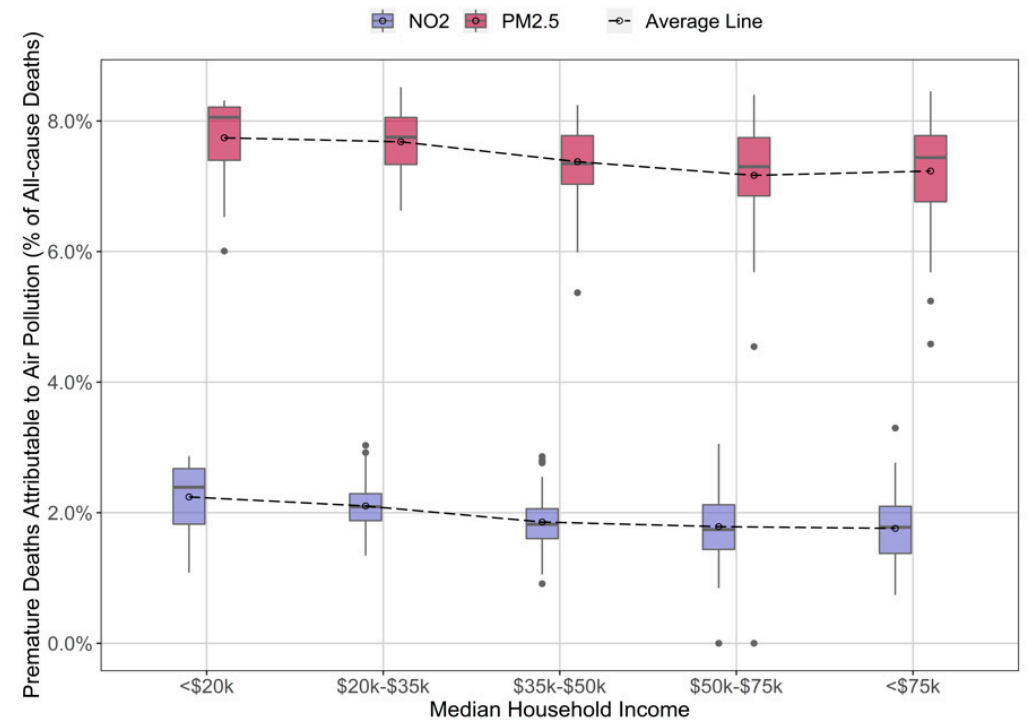

(a)

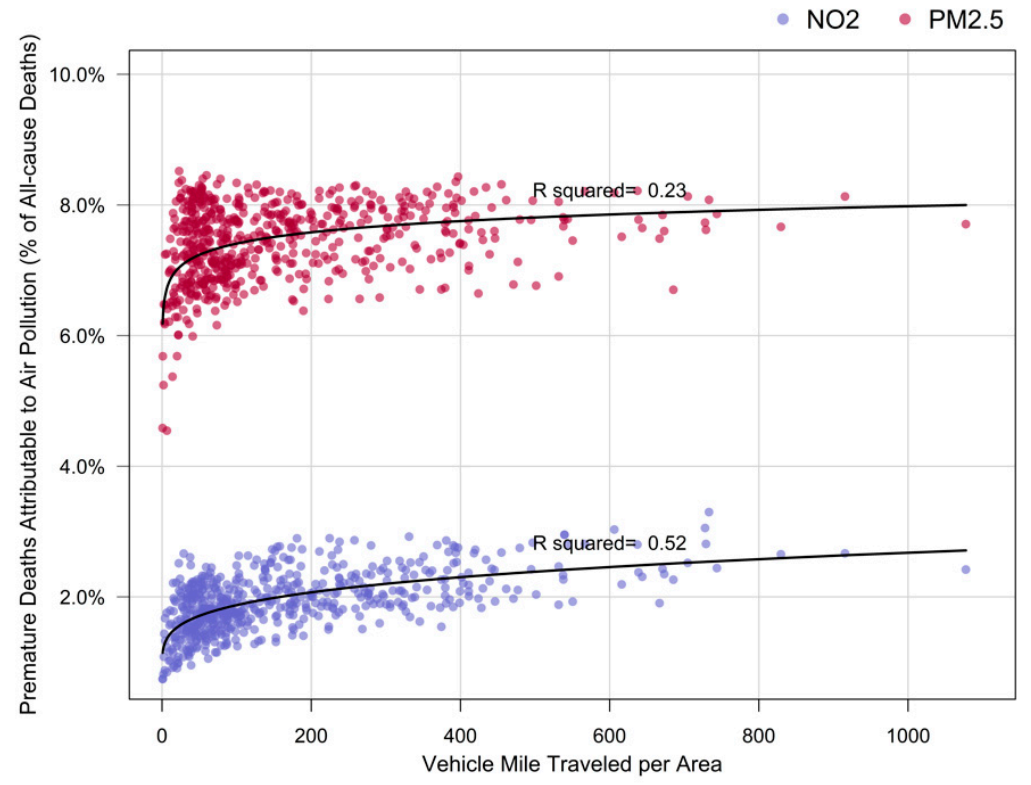

(b)

Figure 5. Variation of the percentage of premature deaths attributable to air pollution from all-cause deaths by (a) median household income, and (b) road traffic. 


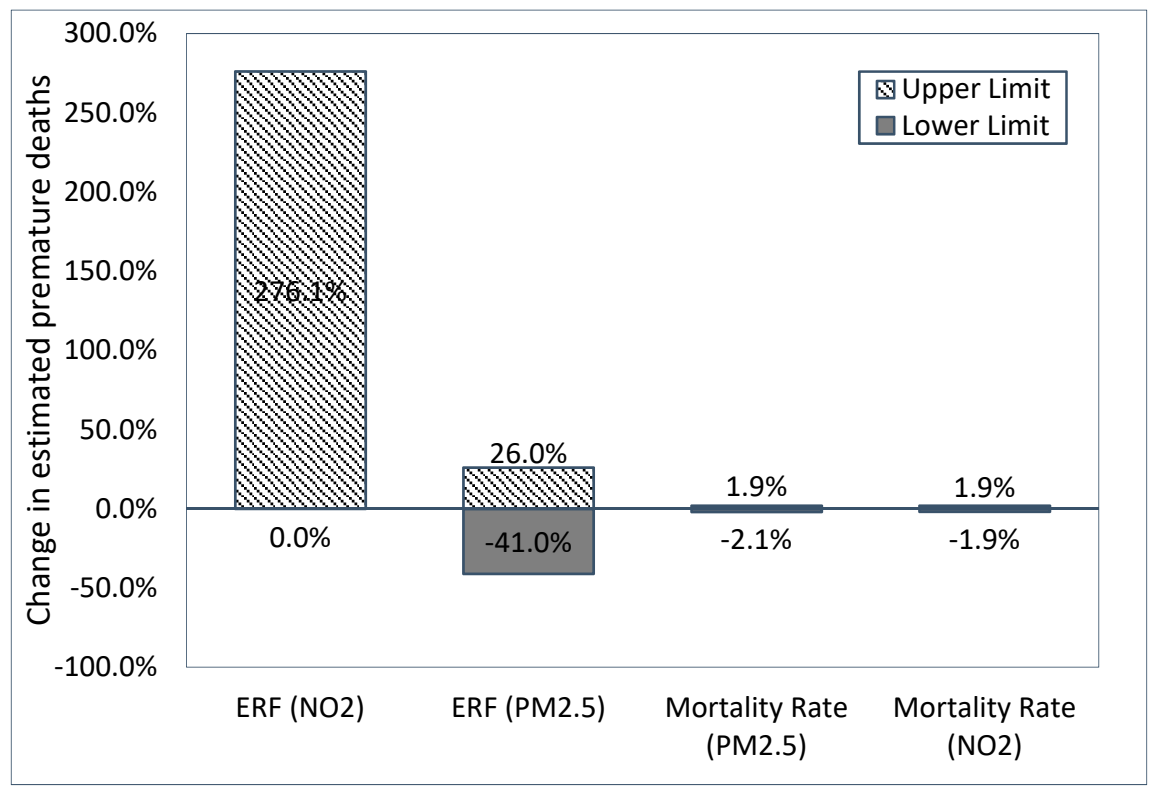

Figure 6. Uncertainty analysis results.

\section{Discussion}

\subsection{Key Findings}

This study sheds light on the health burden attributable to air pollution in the city of Houston, Texas, in the form of premature deaths. The results showed that, in 2010, 631 (95\% CI: 366-809) premature deaths were attributable to $\mathrm{PM}_{2.5}$ and 159 (95\% CI: 0-609) premature deaths were attributable to $\mathrm{NO}_{2}$. The estimated number of premature deaths from $\mathrm{PM}_{2.5}$ and $\mathrm{NO}_{2}$ can be translated into $7.3 \%$ and $1.8 \%$ from all-cause premature deaths in the city, respectively. The ratio of premature deaths attributable to $\mathrm{PM}_{2.5}$ is higher than the death rate caused by diabetes mellites, Alzheimer's disease, or motor vehicle crashes in the US $(2.8 \%, 3.4 \%$, and $4.9 \%$, respectively, in 2010 according to [31]), while the ratio of premature deaths form $\mathrm{NO}_{2}$ is comparable with the death rate from suicide as well as influenza and pneumonia (1.6\% and $2.0 \%$ in 2010 according to [31]). Complying with the WHO air quality guideline values for $\mathrm{PM}_{2.5}\left(10 \mu \mathrm{g} / \mathrm{m}^{3}\right)$ and the NAAQS criteria for $\mathrm{PM}_{2.5}\left(12 \mu \mathrm{g} / \mathrm{m}^{3}\right)$ could prevent $82(95 \% \mathrm{CI}$ : 42-95) and 8 (95\% CI: 6-10) premature deaths in Houston, in 2010.

We found that the burden of premature deaths from air pollution was higher in the census tracts located in the CBD. Additionally, a similarity between the road traffic spatial variation and the ratio of premature deaths attributable to air pollutants was demonstrated. We showed an inverse correlation between the median household income and the ratio of premature deaths attributable to air pollution. The ratio of premature deaths attributable to air pollution decreases by $10 \%$ when the household's median income increases from $\$ 20,000$ to $\$ 75,000$. This is due the higher exposure to air pollutants at census tracts with lower median household income. In addition, the baseline rates of mortality were shown to be higher in communities with lower socioeconomic characteristics [44-46]. Unfortunately, we had no other source of mortality data with a finer spatial resolution, which is a common limitation in similar burden of disease assessment studies. Additionally, a positive relation between road traffic and premature deaths attributable to air pollution was shown: the more vehicles passing through a squared mile of a census tract, the higher the risk of deaths from air pollution. The stronger relationship between the ratio of premature deaths attributable to $\mathrm{NO}_{2}$ and VMTA compared to the ratio of premature deaths attributable to $\mathrm{PM}_{2.5}$ and VMTA is in agreement with the fact that road traffic is responsible for a more significant portion of $\mathrm{NO}_{2}$ than $\mathrm{PM}_{2.5}\left(68 \%\right.$ of $\mathrm{NO}_{2}$ in Beijing, China [47] and $40 \%$ of $\mathrm{NO}_{2}$ in Jamshedpur, India [48] and $56 \%$ of $\mathrm{NO}_{2}$ in European cities [49] while in the US, traffic contributed to $38 \%$ of all nitrogen oxide (NOx) emissions [50]). A higher level of uncertainty was observed in the 
$\mathrm{NO}_{2}$ BoD analysis which is in line with the less precise association between premature deaths and $\mathrm{NO}_{2}$ in epidemiological studies. This implies that the evidence on premature mortality attributable to $\mathrm{PM}_{2.5}$ is more reliable compared to $\mathrm{NO}_{2}$, given the stronger association between $\mathrm{PM}_{2.5}$ and mortality, and also importantly the stronger case for biological plausibility.

\subsection{Strengths and Limitations}

In this study, we estimated the premature deaths attributable to air pollutants at the census tract level which enabled us to better investigate the spatial distribution of attributable deaths. The air pollution concentrations were estimated at a relatively high resolution (census block) and then converted to a lower resolution (census tract). We also investigated premature deaths attributable to $\mathrm{NO}_{2}$ and $\mathrm{PM}_{2.5}$ by the level of road traffic (VMTA) passing through the census tracts and in the catchment area around the census tract where we expect traffic to be most influential. This approach can be considered as a more feasible alternative to full-chain modeling which allows representing the role of traffic-related air pollution in public health. We compared the reliability of the premature death estimates attributable to $\mathrm{NO}_{2}$ and $\mathrm{PM}_{2.5}$.

However, this study has limitations. We assumed the air pollution concentrations do not spatially vary within a census tract which implies that all populations living in a census tract are exposed to the same average concentration level. To assign the mortality data (available at the county level) to a census tract, we assumed that the mortality rate is constant across the census tract located within a county. Based on that, the mortality cases were distributed between the census tracts according to their population. The extracted ERFs were estimated for adults older than 30 years, and so the potential deaths in the younger population were not quantified. Our approach may, therefore, result in underestimating the health impacts of air pollution in Houston. It is also important to note that the health impacts of $\mathrm{PM}_{2.5}$ and $\mathrm{NO}_{2}$ cannot be added up because of the overlap in their biological pathways to adverse health outcomes. Although we showed a relationship between road traffic and deaths attributable to air pollution, no conclusion can be drawn on the contribution of traffic-related air pollution to public health impacts as we did not use an approach that allows source apportionment. In addition, while the LUR predicts air pollution with fairly high accuracy, it considers all sources of air pollution and we could not parse out the exact contribution of traffic from other sources in the exposure and associated BoD. Our study used the median household income at the census tract level to stratify the BoD estimates. This socioeconomic indicator can be a proxy for different factors which not only affect the exposure to air pollution but also the human response to those exposures. These factors include ethnicity, diet, stress and violence exposures, and access to health care where ethnicity is particularly important in US [51]. Previous work using the same air pollution models we employed in our analysis showed that ethnicity is indeed an important factor explaining the disparities in $\mathrm{NO}_{2}$ concentrations across the contiguous US, which were larger by race/ethnicity than by income [52]. Finally, because of the limitations in the availability of ADT data, 2011 data was used and we assumed that the spatial variation of traffic did not change from 2010 to 2011.

\subsection{Policy and Research Recommendations}

A number of strategies have been discussed in the literature to improve air quality and consequently reduce adverse health impacts, e.g., imposing regulations for air quality control, reducing road traffic-related emissions, and controlling energy generation related emissions as well as greenhouse gas emissions [53]. Among others, traffic-related emissions have been shown to have the most significant impacts on air quality and subsequent health impacts [53]. Therefore, travel demand management (TDM) policies to control the traffic passing through air pollution hotspots in cities, i.e., census tracts with a higher level of exposure and detrimental health impacts, can be efficient solutions to improve public health. Improving public transport, improving infrastructure for active transportation, parking control, road pricing, and prohibiting car traffic are some of the TDM policies that have been practiced in cities [54]. The results of this study underscore the necessity of conducting $\mathrm{BoD}$ and health impact 
assessments of transportation-related projects and designs. The results of such studies can contribute to the cost-benefit analysis of the transportation project and help the city to make more informed decisions.

To estimate the contribution of the traffic-related air pollution more accurately, future research can conduct a full-chain BoD assessment comprising transportation modeling, emission modeling, dispersion modeling, exposure assignment, and finally assessing attributable health impacts. Similar studies can be conducted to evaluate the air pollution and health impacts of new technologies (e.g., electric and hybrid vehicles with less emission rates). Additionally, the comparison between air pollution health impacts and other health risk factors in cities can promote dialogue about air pollution health impacts and support decisions to sustainabily develop cities.

\section{Conclusions}

Quantifying the health impacts of air pollution may support decision-makers, city planners, and public health practitioners to mitigate adverse health impacts and ensure that the most vulnerable populations are not the most impacted. In this study, we quantified the health impacts of air pollution in the form of premature deaths, at the census tract level, in the city of Houston, Texas. We investigated the role of road traffic and socioeconomic status in the health burden attributable to ambient air pollution. A total of $7.3 \%$ and $1.8 \%$ of all-cause deaths in Houston were attributable to $\mathrm{PM}_{2.5}$ and $\mathrm{NO}_{2}$, in 2010 , respectively. We showed that $0.9 \%$ of the premature deaths attributable to $\mathrm{PM}_{2.5}$ can be prevented by complying with the WHO air quality guideline value. Deaths attributable to air pollution were higher in the city's CBD, and in a census tract with a higher level of exposure to road traffic, especially in the case of $\mathrm{NO}_{2}$. Additionally, we found that premature deaths attributable to air pollution were higher in areas with lower income households. The findings of this study underline the importance of assessing the $\mathrm{BoD}$ attributable to air pollution and its spatial distribution across cities to support sustainable development.

Author Contributions: Conceptualization, H.K. and S.S. methodology, S.S. and H.K. formal analysis, S.S. investigation, S.S. resources, S.S. and H.K. data curation, S.S. writing-original draft preparation, S.S. writing-reviewing and editing, S.S. and H.K. visualization, S.S. supervision, H.K. and J.Z. project administration, H.K. funding acquisition, H.K. and J.Z. All authors have read and agreed to the published version of the manuscript.

Funding: This research was made possible by funding from the Texas A\&M Transportation Institute's (TTI) Center for Advancing Research in Transportation Emissions, Energy, and Health (CARTEEH), a U.S. Department of Transportation's University Transportation Center with the grant number (69A3551747128).

Acknowledgments: We would like to thank Matthew Bechle and Julian Marshall at the University of Washington for providing the 2010 air pollution exposure estimates.

Conflicts of Interest: The authors declare no conflict of interest.

\section{References}

1. United Nations. World Urbanization Prospects: The 2014 Revision-Highlights; United Nations: Geneva, Switzerland, 2014; Available online: https:/population.un.org/wup/Publications/Files/WUP2018-KeyFacts. pdf (accessed on 20 July 2020).

2. Wheeler, S.M.; Beatley, T. Sustainable Urban Development Reader; Routledge: New York, NY, USA, 2014.

3. Robert, K.W.; Parris, T.M.; Leiserowitz, A.A. What is sustainable development? Goals, indicators, values, and practice. Environ. Sci. Policy Sustain. Dev. 2005, 47, 8-21. [CrossRef]

4. Colvile, R.; Kaur, S.; Britter, R.; Robins, A.; Bell, M.; Shallcross, D.; Belcher, S. Sustainable development of urban transport systems and human exposure to air pollution. Sci. Total Environ. 2004, 334, 481-487. [CrossRef]

5. Liu, Q.; Baumgartner, J.; de Foy, B.; Schauer, J.J. A global perspective on national climate mitigation priorities in the context of air pollution and sustainable development. City Environ. Interact. 2019, 1, 100003. [CrossRef]

6. World Health Organization. Who Global Urban Ambient Air Pollution Database (Update 2016); World Health Organization: Geneva, Switzerland, 2016; Available online: https://www.who.int/phe/health_ topics/outdoorair/databases/cities/en/ (accessed on 20 July 2019). 
7. Raaschou-Nielsen, O.; Andersen, Z.J.; Beelen, R.; Samoli, E.; Stafoggia, M.; Weinmayr, G.; Hoffmann, B.; Fischer, P.; Nieuwenhuijsen, M.J.; Brunekreef, B. Air pollution and lung cancer incidence in 17 european cohorts: Prospective analyses from the european study of cohorts for air pollution effects (escape). Lancet Oncol. 2013, 14, 813-822. [CrossRef]

8. Kurt, O.K.; Zhang, J.; Pinkerton, K.E. Pulmonary health effects of air pollution. Curr. Opin. Pulm. Med. 2016, 22, 138. [CrossRef] [PubMed]

9. Bhalla, K.; Shotten, M.; Cohen, A.; Brauer, M.; Shahraz, S.; Burnett, R.; Leach-Kemon, K.; Freedman, G.; Murray, C. Transport for Health: The Global Burden of Disease from Motorized Road Transport; World Bank Group: Washington, DC, USA, 2014; Available online: http://documents.worldbank.org/curated/en/ 984261468327002120/Transport-for-health-the-global-burden-of-disease-from-motorized-road-transport (accessed on 7 February 2020).

10. Kampa, M.; Castanas, E. Human health effects of air pollution. Environ. Pollut. 2008, 151, 362-367. [CrossRef] [PubMed]

11. Cesaroni, G.; Forastiere, F.; Stafoggia, M.; Andersen, Z.J.; Badaloni, C.; Beelen, R.; Caracciolo, B.; de Faire, U.; Erbel, R.; Eriksen, K.T. Long term exposure to ambient air pollution and incidence of acute coronary events: Prospective cohort study and meta-analysis in 11 European cohorts from the escape project. BMJ 2014, 348, f7412. [CrossRef] [PubMed]

12. Cesaroni, G.; Badaloni, C.; Gariazzo, C.; Stafoggia, M.; Sozzi, R.; Davoli, M.; Forastiere, F. Long-term exposure to urban air pollution and mortality in a cohort of more than a million adults in rome. Environ. Health Perspect. 2013, 121, 324-331. [CrossRef]

13. World Health Organization. Fact Sheet: Ambient (Outdoor) Air Quality and Health. 2018. Available online: https://www.who.int/en/news-room/fact-sheets/detail/ambient-(outdoor)-air-quality-and-health (accessed on 1 May 2019).

14. Lelieveld, J.; Evans, J.S.; Fnais, M.; Giannadaki, D.; Pozzer, A. The contribution of outdoor air pollution sources to premature mortality on a global scale. Nature 2015, 525, 367. [CrossRef]

15. Tainio, M. Burden of disease caused by local transport in warsaw, poland. J. Transp. Health 2015, 2, $423-433$. [CrossRef]

16. Holnicki, P.; Tainio, M.; Kałuszko, A.; Nahorski, Z. Burden of mortality and disease attributable to multiple air pollutants in warsaw, poland. Int. J. Environ. Res. Public Health 2017, 14, 1359. [CrossRef] [PubMed]

17. De Sá, T.H.; Tainio, M.; Goodman, A.; Edwards, P.; Haines, A.; Gouveia, N.; Monteiro, C.; Woodcock, J. Health impact modelling of different travel patterns on physical activity, air pollution and road injuries for são paulo, brazil. Environ. Int. 2017, 108, 22-31.

18. Zhang, C.; Ding, R.; Xiao, C.; Xu, Y.; Cheng, H.; Zhu, F.; Lei, R.; Di, D.; Zhao, Q.; Cao, J. Association between air pollution and cardiovascular mortality in Hefei, China: A time-series analysis. Environ. Pollut. 2017, 229, 790-797. [CrossRef] [PubMed]

19. Mueller, N.; Rojas-Rueda, D.; Khreis, H.; Cirach, M.; Milà, C.; Espinosa, A.; Foraster, M.; Mceachan, R.R.; Kelly, B.; Wright, J. Socioeconomic inequalities in urban and transport planning related exposures and mortality: A health impact assessment study for bradford, UK. Environ. Int. 2018, 121, 931-941. [CrossRef] [PubMed]

20. Mueller, N.; Rojas-Rueda, D.; Basagaña, X.; Cirach, M.; Cole-Hunter, T.; Dadvand, P.; Donaire-Gonzalez, D.; Foraster, M.; Gascon, M.; Martinez, D. Urban and transport planning related exposures and mortality: A health impact assessment for cities. Environ. Health Perspect. 2016, 125, 89-96. [CrossRef] [PubMed]

21. Khreis, H.; de Hoogh, K.; Nieuwenhuijsen, M.J. Full-chain health impact assessment of traffic-related air pollution and childhood asthma. Environ. Int. 2018, 114, 365-375. [CrossRef]

22. Mueller, N.; Rojas-Rueda, D.; Basagaña, X.; Cirach, M.; Cole-Hunter, T.; Dadvand, P.; Donaire-Gonzalez, D.; Foraster, M.; Gascon, M.; Martínez, D. Health impacts related to urban and transport planning: A burden of disease assessment. Environ. Int. 2017, 107, 243-257. [CrossRef]

23. Kheirbek, I.; Haney, J.; Douglas, S.; Ito, K.; Matte, T. The contribution of motor vehicle emissions to ambient fine particulate matter public health impacts in new york city: A health burden assessment. Environ. Health 2016, 15, 89. [CrossRef]

24. Tainio, M.; de Nazelle, A.J.; Götschi, T.; Kahlmeier, S.; Rojas-Rueda, D.; Nieuwenhuijsen, M.J.; de Sá, T.H.; Kelly, P.; Woodcock, J. Can air pollution negate the health benefits of cycling and walking? Prev. Med. 2016, 87, 233-236. [CrossRef] 
25. Khreis, H.; Warsow, K.M.; Verlinghieri, E.; Guzman, A.; Pellecuer, L.; Ferreira, A.; Jones, I.; Heinen, E.; Rojas-Rueda, D.; Mueller, N. The health impacts of traffic-related exposures in urban areas: Understanding real effects, underlying driving forces and co-producing future directions. J. Transp. Health 2016, 3, $249-267$. [CrossRef]

26. Brønnum-Hansen, H.; Bender, A.M.; Andersen, Z.J.; Sørensen, J.; Bønløkke, J.H.; Boshuizen, H.; Becker, T.; Diderichsen, F.; Loft, S. Assessment of impact of traffic-related air pollution on morbidity and mortality in copenhagen municipality and the health gain of reduced exposure. Environ. Int. 2018, 121, 973-980. [CrossRef] [PubMed]

27. Goodkind, A.L.; Tessum, C.W.; Coggins, J.S.; Hill, J.D.; Marshall, J.D. Fine-scale damage estimates of particulate matter air pollution reveal opportunities for location-specific mitigation of emissions. Proc. Natl. Acad. Sci. USA 2019, 116, 8775-8780. [CrossRef] [PubMed]

28. Health Effects Institute. Traffic-related Air Pollution: A Critical Review of the Literature on Emissions, Exposure, and Health Effects; Health Effects Institute: Boston, MA, USA, 2010.

29. World Population Review. Houston, Texas Population. 2019. Available online: http://worldpopulationreview. com/us-cities/houston-population/ (accessed on 1 May 2019).

30. Doughty, J. Mortality in terms of lost years of life. Can. J. Public Health/Revue Can. de Sante'e Publique 1951, 42, 134-141.

31. Murphy, S.L.; Xu, J.; Kochanek, K.D. Deaths: Final Data for 2010. 2013. Available online: https://www.cdc. gov/nchs/data/nvsr/nvsr62/nvsr62_06.pdf (accessed on 20 July 2019).

32. Alotaibi, R.; Bechle, M.; Marshall, J.D.; Ramani, T.; Zietsman, J.; Nieuwenhuijsen, M.J.; Khreis, H. Traffic related air pollution and the burden of childhood asthma in the contiguous united states in 2000 and 2010. Environ. Int. 2019, 127, 858-867. [CrossRef]

33. WHO. Air Quality Guidelines: Global Update 2005: Particulate Matter, Ozone, Nitrogen Dioxide, and Sulfur Dioxide; WHO: Geneva, Switzerland, 2006.

34. Bechle, M.J.; Millet, D.B.; Marshall, J.D. National spatiotemporal exposure surface for $\mathrm{NO}_{2}$ : Monthly scaling of a satellite-derived land-use regression, 2000-2010. Environ. Sci. Technol. 2015, 49, 12297-12305. [CrossRef]

35. Beelen, R.; Hoek, G.; Pebesma, E.; Vienneau, D.; de Hoogh, K.; Briggs, D.J. Mapping of background air pollution at a fine spatial scale across the european union. Sci. Total Environ. 2009, 407, 1852-1867. [CrossRef]

36. Hystad, P.; Setton, E.; Cervantes, A.; Poplawski, K.; Deschenes, S.; Brauer, M.; van Donkelaar, A.; Lamsal, L.; Martin, R.; Jerrett, M. Creating national air pollution models for population exposure assessment in canada. Environ. Health Perspect. 2011, 119, 1123-1129. [CrossRef]

37. Vienneau, D.; de Hoogh, K.; Bechle, M.J.; Beelen, R.; van Donkelaar, A.; Martin, R.V.; Millet, D.B.; Hoek, G.; Marshall, J.D. Western european land use regression incorporating satellite-and ground-based measurements of $\mathrm{NO}_{2}$ and $\mathrm{PM}_{10}$. Environ. Sci. Technol. 2013, 47, 13555-13564. [CrossRef]

38. Kim, S.-Y.; Bechle, M.; Hankey, S.; Sheppard, L.; Aa, J.a.M.S. Parsimonious Approach for Estimating Ambient Concentrations of Criteria Pollutants in the Contiguous U.S. Unpublished Manuscript.

39. World Health Organization. Review of Evidence on Health Aspects of Air Pollution-Revihaap Project: Final Technical Report; WHO European Centre for Environment and Health: Geneva, Switzerland, 2013. Available online: https://www.ncbi.nlm.nih.gov/books/NBK361807/ (accessed on 20 July 2019).

40. Beelen, R.; Raaschou-Nielsen, O.; Stafoggia, M.; Andersen, Z.J.; Weinmayr, G.; Hoffmann, B.; Wolf, K.; Samoli, E.; Fischer, P.; Nieuwenhuijsen, M. Effects of long-term exposure to air pollution on natural-cause mortality: An analysis of 22 european cohorts within the multicentre escape project. Lancet 2014, 383, 785-795. [CrossRef]

41. World Health Organization. Who Expert Meeting: Methods and Tools for Assessing the Health Risks of Air Pollution at Local, National and International Level; WHO Regional Office for Europe: Copenhagen, Denmark, 2014; Available online: http://www.euro.who.int/_data/assets/pdf_file/0010/263629/WHO-Expert-MeetingMethods-and-tools-for-assessing-the-health-risks-of-air-pollution-at-local,-national-and-internationallevel.pdf?ua=1 (accessed on 20 July 2019).

42. Environmental Protection Agency. Primary and Secondary National Ambient Air Quality Standards for Oxides of Nitrogen and Sulfur, 36 Fed. Reg. 8186 (Final Rule 30 April 1971).

43. Environmental Protection Agency. National Ambient Air Quality Standards for Particulate Matter, 78 Fed. Reg. 3085 (Final Rule 15 January 2013) (to be codified at 40 C.F.R. pts 50, 51, 52). 
44. Anderson, R.T.; Sorlie, P.; Backlund, E.; Johnson, N.; Kaplan, G.A. Mortality effects of community socioeconomic status. Epidemiology 1997, 8, 42-47. [CrossRef] [PubMed]

45. Pickett, K.E.; Wilkinson, R.G. Income inequality and health: A causal review. Soc. Sci. Med. 2015, 128, 316-326. [CrossRef] [PubMed]

46. Wilkinson, R.G.; Pickett, K.E. Income inequality and socioeconomic gradients in mortality. Am. J. Public Health 2008, 98, 699-704. [CrossRef]

47. Hao, J.; Wu, Y.; Fu, L.; He, D.; He, K. Source contributions to ambient concentrations of co and nox in the urban area of beijing. J. Environ. Sci. Health Part A 2001, 36, 215-228. [CrossRef]

48. Bhanarkar, A.; Goyal, S.; Sivacoumar, R.; Rao, C.C. Assessment of contribution of $\mathrm{SO}_{2}$ and $\mathrm{NO}_{2}$ from different sources in jamshedpur region, india. Atmos. Environ. 2005, 39, 7745-7760. [CrossRef]

49. Sundvor, I.; Balaguer, N.C.; Viana, M.; Querol, X.; Reche, C.; Amato, F.; Mellios, G.; Guerreiro, C. Road traffic's Contribution to Air Quality in European Cities. Etc/acm Technical Paper 2012/14 November 2012. The European Topic Centre on Air Pollution and Climate Change Mitigation (ETC/ACM) (a Consortium of European Institutes under Contract of the European Environment Agency). 2012. Available online: https://www.eionet.europa.eu/etcs/etc-atni/products/etc-atni-reports/etcacm_tp_2012_14_traffic_ contribution_city_aq (accessed on 20 July 2019).

50. U.S. Department of Transportation. Transporation Air Quality Selected Facts and Figures; U.S. Department of Transportation: Washington, DC, USA, 2016. Available online: https://www.fhwa.dot.gov/environment/air_ quality/publications/fact_book/index.cfm (accessed on 20 July 2019).

51. Christina, H.F.; Brugge, D. Environmental justice: Disproportionate impacts of transportation on vulnerable communities. In Traffic-Related Air Pollution: Emissions, Human Exposures, and Health; Khreis, H., Nieuwenhuijsen, M., Eds.; Elsevier: Amsterdam, The Netherlands, 2020.

52. Clark, L.P.; Millet, D.B.; Marshall, J.D. Changes in transportation-related air pollution exposures by race-ethnicity and socioeconomic status: Outdoor nitrogen dioxide in the united states in 2000 and 2010. Environ. Health Perspect. 2017, 125, 097012. [CrossRef] [PubMed]

53. Wang, L.; Zhong, B.; Vardoulakis, S.; Zhang, F.; Pilot, E.; Li, Y.; Yang, L.; Wang, W.; Krafft, T. Air quality strategies on public health and health equity in europe-A systematic review. Int. J. Environ. Res. Public Health 2016, 13, 1196. [CrossRef]

54. Gärling, T.; Schuitema, G. Travel demand management targeting reduced private car use: Effectiveness, public acceptability and political feasibility. J. Soc. Issues 2007, 63, 139-153. [CrossRef] 